\title{
Decline in lung function and mortality: The Busselton Health Study
}

Gerard Ryan, Matthew W Knuiman, Mark L Divitini, Alan James, A W Musk, Helen C Bartholomew

\begin{abstract}
Background-There is a direct association between level of lung function, measured by forced expiratory volume in 1 second $\left(\mathrm{FEV}_{1}\right)$ and mortality rates. A low $\mathrm{FEV}_{1}$ may result from an increased decline in $\mathrm{FEV}_{1}$ with age, which may be an independent predictor of mortality. Objective-To examine the association between decline in $\mathrm{FEV}_{1}$ and mortality in a cohort from a community health study.

Setting and methods-From five cross sectional studies in Busselton between 1969 and 1981 a cohort of 751 men and 940 women was identified who had three assessments of lung function over a six year period and had other health related data collected. Each subject's average $\mathrm{FEV}_{1}$ and decline in $\mathrm{FEV}_{1}$ (litre/year) were calculated from these three measurements. Mortality follow up to December 1995 was obtained. Cause of death was taken as the certified cause of death from the death certificate using ICD9 categories.
\end{abstract}

Results-The average decline in $\mathrm{FEV}_{1}$ was 0.04 litre per year $(S D=0.07)$ for men and 0.03 litre per year $(S D=0.06)$ for women. Average $\mathrm{FEV}_{1}$ was significantly associated with all cause and cardiovascular disease mortality in both sexes. In women there was a significant association between decline in $\mathrm{FEV}_{1}$ and death from all causes, after adjusting for average $\mathrm{FEV}_{1}$, age, smoking, coronary heart disease, and cardiovascular disease risk factors; a 0.05 litre per year increase in the rate of decline of $\mathrm{FEV}_{1}$ increased the risk of death for all causes by 1.23 (95\% confidence interval 1.06, 1.44). In men the effect of decline in $\mathrm{FEV}_{1}$ on death rate was less; for all men the hazard ratio for a 0.05 litre/year greater decline in $\mathrm{FEV}_{1}$ was 1.19 $(0.99,1.21)$.

Conclusion-Decline in lung function, measured by $F E V_{1}$ is a predictor of death, independent of average $F E V_{1}$ and risk factors for cardiovascular disease.

(F Epidemiol Community Health 1999;53:230-234)

Pulmonary Physiology Sir Charles Gairdner Hospital

A James

Correspondence to: Associate Professor M W Knuiman, Department of Public Health, University of Western Australia, Nedlands WA 6907, Australia.

Accepted for publication 5 October 1998 level of $\mathrm{FEV}_{1}$ at any time in an adult will be determined by the level attained by growth from childhood to early adulthood, the duration of the plateau of $\mathrm{FEV}_{1}$ in early adult life, and the subsequent rate of decline with age. ${ }^{18}$

Two published studies and an abstract publication have shown evidence that decline in lung function is a predictor of mortality. ${ }^{19-21}$ The Honolulu Heart Study showed the rate of decline in lung function over a six year period was a significant predictor of total mortality in men and that the association was stronger for current or ever smokers than never smokers. ${ }^{19}$ In the Baltimore Longitudinal Study of Aging, the rate of decline in lung function was an independent predictor of mortality from coronary heart disease in men who were initially free of coronary heart disease. ${ }^{20}$ In white adults from six cities in the United States the all cause mortality was highest in both men and women with the highest declines in $\mathrm{FEV}_{1} \cdot{ }^{21}$ The mechanism for this association has not been determined.

Lung function was measured in five cross sectional surveys of men and women in the town of Busselton in Western Australia from 1969 to 1981 . The aim of this study was to examine the association between decline in lung function and mortality and to see if any association could be explained by smoking or cardiovascular disease risk factors.

\section{Methods}

The Busselton health study has comprised a series of cross sectional surveys of adults and children from the Shire of Busselton. Busselton is coastal, rural, has a Mediterranean type climate and the population is predominantly of European origin. Cross sectional surveys of adults listed on the electoral roll were undertaken at intervals of three years from 1966 to 1981. Enrollment to vote is compulsory in Australia. The cohort for this longitudinal study comprises 751 men and 940 women, aged 25 to 79 years, who first attended a survey in 1969 or 1972 or 1975 and attended two further surveys and therefore had a baseline and two follow up measurements of lung function over a six year period.

The health related data gathered in each survey included demographic variables, general health and lifestyle variables, health history variables, and physical, biochemical, haematological, and immunological measurements. General descriptions of the surveys and two reviews of some results have been published. .2-25 $^{25}$

$\mathrm{FEV}_{1}$ and forced vital capacity (FVC) were measured in all three surveys using a 
Table 1 Subject characteristics

\begin{tabular}{lll}
\hline Variable $^{*}$ & Men $(n=751)$ & Women $(n=940)$ \\
\hline Age (y) & $49.4(14.0)$ & $48.7(13.1)$ \\
Average FEV (litre) $_{\text {Decline FEV }}$ (litre/y) & $3.26(0.86)$ & $2.35(0.61)$ \\
Asthma (\%) & $0.04(0.07)$ & $0.03(0.06)$ \\
Systolic blood pressure (mm Hg) & 3.9 & 6.4 \\
Diastolic blood pressure (mm Hg) & $136.5(19.3)$ & $133.0(21.2)$ \\
Cholesterol (mmol/1) & $80.0(13.0)$ & $77.8(12.6)$ \\
Body mass index (kg/m $\left.{ }^{2}\right)$ & $5.87(1.13)$ & $6.10(1.32)$ \\
Smoking & $25.6(3.1)$ & $24.8(4.1)$ \\
$\quad$ Never (\%) & 34.2 & 73.3 \\
$\quad$ Ex (\%) & 35.3 & 12.1 \\
$\quad$ Current (\%) & 30.5 & 14.6 \\
Alcohol & 16.2 & 42.6 \\
$\quad$ Non (\%) & 2.8 & - \\
$\quad$ Ex (\%) & 49.3 & 49.5 \\
$\quad$ Light (\%) & 31.7 & 8.0 \\
$\quad$ Heavy (\%) & 5.6 & 9.6 \\
Blood pressure treatment (\%) & 7.2 & 6.6 \\
Coronary heart disease (\%) & & \\
\hline * & & \\
\hline
\end{tabular}

$\star$ Results expressed as mean (SD) or percentage of total.

McDermott dry spirometer. All values obtained were the volume at body temperature and pressure and saturated with water vapour corrected (BTPS). The $\mathrm{FEV}_{1}$ from each survey used for analysis was the highest from three successive maximum expiratory manoeuvres provided that at least two recordings were within $10 \%$ of each other. Decline in lung function was taken as the change of $\mathrm{FEV}_{1}$ in litre per year using the slope of the linear regression equation of this highest $F E V_{1}$ from each of three surveys over the six year period.

Participants were asked to report if they had ever been treated for bronchial asthma (1969 and 1972) or asthma (1975). Smoking, alcohol consumption, and use of antihypertensive medication were obtained from a questionnaire. This information was not checked by other sources. Smoking was categorised as never, ex or current smokers. People consuming less than 20 grams of alcohol per day were classified as light drinkers and those consuming 20 or more grams per day as heavy drinkers.

Systolic and diastolic blood pressure were measured by mercury sphygmomanometer after five minutes in a resting position. Height and weight were measured and body mass index (weight $(\mathrm{kg})$ divided by height (metres) squared) was calculated. Serum total cholesterol was determined from a fasting blood sample. Coronary heart disease was determined from the Rose questionnaire for angina and myocardial infarction, a 12 lead electrocardiogram, and a self reported confirmation that their doctor had said they had heart disease. ${ }^{26}$
KEY POINTS

- There is an association between the level of $\mathrm{FEV}_{1}$ and mortality rate.

- A low $\mathrm{FEV}_{1}$ may be attributable to a more rapid decline in $\mathrm{FEV}_{1}$ during adult life.

- The average decline in $\mathrm{FEV}_{1}$ in a rural population was 0.04 litre/year in men and 0.03 litre/year in women.

- The greater the rate of decline in $\mathrm{FEV}_{1}$ the greater the rate of death from all causes, independent of average $\mathrm{FEV}_{1}$, cigarette smoking and other cardiovascular risk factors.

- The association between decline in $\mathrm{FEV}_{1}$ and mortality was stronger in women than in men.

Deaths were obtained by searching the Death Register to 31 December 1995. Deaths among survey participants were identified by linkage to the Death Register for Western Australia and through relatives. Survival status was confirmed by linkage to the electoral roll, Telecom White Pages, and through relatives. The length of follow up ranged from 20 years for 1975 survey participants to 26 years for 1969 survey participants. The underlying cause of death was determined from the death certificates as coded by nosologists at the Australian Bureau of Statistics. Death was attributed to cardiovascular disease if the underlying cause of death was coded to ICD9 410-459 and to coronary heart disease if coded 410-414. There were too few deaths attributable to respiratory disease for analysis.

Cox proportional hazards regression was used to assess the relation between average $\mathrm{FEV}_{1}$ and decline in $\mathrm{FEV}_{1}$ (simultaneously) and mortality after adjusting for age, height, smoking, coronary heart disease, and cardiovascular risk factors. ${ }^{27}$ The effect of average $\mathrm{FEV}_{1}$ or decline in $\mathrm{FEV}_{1}$ on mortality was expressed as a hazard ratio (relative risk). If the $95 \%$ confidence interval for the hazard ratio excludes 1.0 then the estimated hazard ratio was considered statistically significant. Three mortality rates were analysed; all causes, cardiovascular disease, and coronary heart disease. All variables were taken from the first assessment for each person except for average $\mathrm{FEV}_{1}$, which was the average of the highest $\mathrm{FEV}_{1}$ measured at each of their three survey attendances, and for decline in $\mathrm{FEV}_{1}$ (litre/

Table 2 Number of deaths in men and women by categories of tobacco smoking

\begin{tabular}{|c|c|c|c|c|c|c|}
\hline & \multicolumn{3}{|l|}{ Men } & \multicolumn{3}{|l|}{ Women } \\
\hline & Never smoker & Ex smoker & Current smoker & Never smoker & Ex smoker & Current smoker \\
\hline Total persons & 257 & 265 & 229 & 689 & 114 & 137 \\
\hline $\operatorname{Age}(\mathrm{y})^{\star}$ & $44.7(14.1)$ & $55.2(12.9)$ & $48.0(12.6)$ & $49.0(13.7)$ & $48.9(11.6)$ & $46.8(10.7)$ \\
\hline \multicolumn{7}{|l|}{ Deaths } \\
\hline Total & 48 & 109 & 83 & 142 & 21 & 35 \\
\hline Cardiovascular disease & $30(62.5 \%)$ & $54(49.5 \%)$ & $40(48.2 \%)$ & $83(58.4 \%)$ & $11(52.4 \%)$ & $20(57.1 \%)$ \\
\hline Coronary heart disease & $21(43.8 \%)$ & $32(29.4 \%)$ & $28(33.7 \%)$ & $52(36.6 \%)$ & $5(23.8 \%)$ & $10(28.6 \%)$ \\
\hline \multicolumn{7}{|c|}{ Deaths excluding those within 3 years of 6 year assessment } \\
\hline Total & 45 & 99 & 71 & 130 & 20 & 33 \\
\hline Cardiovascular disease & $28(62.2 \%)$ & $51(51.5 \%)$ & $31(43.7 \%)$ & $75(57.7 \%)$ & $11(55.0 \%)$ & $19(57.6 \%)$ \\
\hline Coronary heart disease & $19(42.2 \%)$ & $30(30.3 \%)$ & $22(31.0 \%)$ & $48(36.9 \%)$ & $5(25.0 \%)$ & $10(30.3 \%)$ \\
\hline
\end{tabular}

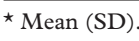


Table 3 Average FEV, and rate of decline of FEV in relation to all cause, cardiovascular disease, and coronary heart disease mortality (excluding deaths within three years of last survey) after adjusting for age, height, smoking, asthma, coronary heart disease, and cardiovascular disease risk factors. Table shows hazard ratio and 95\% confidence interval for a decrease of $1 \mathrm{~L}$ in average FEV and an increase of $0.05 \mathrm{lly}$ in rate of decline of FEV

\begin{tabular}{|c|c|c|c|c|c|c|}
\hline & \multicolumn{2}{|l|}{ All cause } & \multicolumn{2}{|c|}{ Cardiovascular disease } & \multicolumn{2}{|c|}{ Coronary heart disease } \\
\hline & Average $F E V_{1}$ & Decline $F E V_{1}$ & Average FEV $V_{1}$ & Decline FEV & Average FEV & Decline $F E V_{1}$ \\
\hline \multicolumn{7}{|l|}{ Women } \\
\hline Never smoker & $1.46(0.83,2.56)$ & $1.24(1.04,1.48)$ & $0.99(0.46,2.16)$ & $1.19(0.92,1.54)$ & $1.02(0.38,2.73)$ & $1.26(0.92,1.72)$ \\
\hline Ex smoker & $3.09(1.30,7.37)$ & $1.29(0.74,2.26)$ & $1.75(0.49,6.17)$ & $1.36(0.64,2.89)$ & $1.32(0.21,8.24)$ & $1.75(0.56,5.48)$ \\
\hline Current smoker & $1.88(0.74,4.82)$ & $1.08(0.78,1.51)$ & $2.87(0.68,12.04)$ & $1.00(0.63,1.58)$ & $1.33(0.20,8.67)$ & $1.09(0.59,2.04)$ \\
\hline All & $1.77(1.09,2.86)$ & $1.21(1.04,1.41)$ & $1.29(0.66,2.52)$ & $1.17(0.94,1.45)$ & $1.07(0.44,2.58)$ & $1.25(0.95,1.65)$ \\
\hline \multicolumn{7}{|l|}{ Men } \\
\hline Never smoker & $0.92(0.56,1.52)$ & $0.85(0.63,1.14)$ & $0.73(0.38,1.43)$ & $0.84(0.56,1.25)$ & $0.75(0.33,1.74)$ & $0.91(0.57,1.46)$ \\
\hline Ex smoker & $1.37(0.94,2.00)$ & $1.06(0.90,1.25)$ & $1.51(0.86,2.63)$ & $0.93(0.75,1.14)$ & $1.60(0.79,3.23)$ & $0.98(0.72,1.33)$ \\
\hline Current smoker & $1.73(1.16,2.59)$ & $1.15(1.00,1.32)$ & $1.02(0.56,1.84)$ & $1.09(0.90,1.33)$ & $1.33(0.64,2.80)$ & $1.07(0.86,1.32)$ \\
\hline All & $1.42(1.08,1.87)$ & $1.08(0.98,1.20)$ & $1.12(0.75,1.68)$ & $0.99(0.87,1.13)$ & $1.25(0.76,2.06)$ & $1.02(0.86,1.20)$ \\
\hline
\end{tabular}

year). Deaths that occurred within three years of the last of the three measurements of $\mathrm{FEV}_{1}$ were excluded from analysis. The survival time was the number of years from the first survey (1969 or 1972 or 1975) to death or date last known to be alive (usually 31 December 1995). People who had not died (or died from a cause other than the one of interest) were considered censored. The SAS statistical package was used to perform statistical calculations. ${ }^{28}$

\section{Results}

There were 751 men and 940 women who attended for three measurements of lung function over a six year period between 1969 and 1981 (table 1). The high frequencies of never smoking and no alcohol use in women was typical for rural Australia in the period of the study. The average decline in $\mathrm{FEV}_{1}$ was 0.04 litre/year $(S D=0.07)$ for men and 0.03 litre/year $(S D=0.06)$ for women. At the time of first assessment $30.5 \%$ of men and $14.6 \%$ of women were current cigarette smokers. There were a total of 240 deaths in men and 198 deaths in women, with 25 male deaths and 15 female deaths occurring within three years of their final assessment (table 2). Approximately half of the deaths were attributable to cardiovascular disease and about one third of deaths to coronary heart disease.

There was a significant association between average $\mathrm{FEV}_{1}$ and all cause mortality for men and women, after adjusting for smoking, history of asthma, coronary artery disease, and cardiovascular disease risk factors (table 3). The strength of the association was greater in women than in men, the hazard ratio for a decrease in average $\mathrm{FEV}_{1}$ of 1.0 litre was 1.60 for all women and 1.43 in all men. The trend for higher risk of death with average $\mathrm{FEV}_{1}$ was seen for all smoking categories in both sexes apart from men who never smoked cigarettes. The association was statistically significant only for men who were current smokers and women who were ex smokers. The relative risk of death from cardiovascular disease and coronary artery disease was greater, although not statistically significantly greater than 1 , in all categories apart from men who never smoked tobacco.

After adjusting for average $\mathrm{FEV}_{1}$, the decline in $\mathrm{FEV}_{1}$, in litre per year, was significantly associated with death from all causes in women, after further adjusting for age, height, history of asthma, smoking habits, coronary heart disease, and cardiovascular disease risk factors (table 3). An increase in the decline of $\mathrm{FEV}_{1}$ of $50 \mathrm{ml}$ per year was associated with a $22.4 \%$ increased risk of death from all causes (95\% confidence intervals, 5.2\%, 42.6\%). The trend for a greater decline in $\mathrm{FEV}_{1}$ being associated with increased risk of death from cardiovascular and coronary heart disease was seen but not statistically significant.

In men the level of association between decline in $\mathrm{FEV}_{1}$ and death was in general less than in women and not statistically significant for any association. Again, men who never smoked tobacco were different from the other groups with hazard ratio for death being less than 1, however these hazard ratios did not reach the level of statistical significance.

\section{Discussion}

This study provides further evidence for an association between decline in $\mathrm{FEV}_{1}$ and mortality, independent of risk factors for cardiovascular disease, cigarette smoking, and average $\mathrm{FEV}_{1}$. The women in this study had an increased risk of death from all causes that was statistically significant for the whole group and for the group of women who had never smoked tobacco. The women also had similar patterns of association between decline in $\mathrm{FEV}_{1}$ and death resulting from cardiovascular disease and from coronary heart disease. In men there was a similar trend for these associations except for the group who had never smoked tobacco.

Longitudinal studies of $\mathrm{FEV}_{1}$ in populations have allowed observations on normal persons and examination of factors associated with an increased decline in $\mathrm{FEV}_{1} \cdot{ }^{18}$ Estimates of the decline in $\mathrm{FEV}_{1}$ in never smokers show a variation with age; in subjects aged $25-50$ the $\mathrm{FEV}_{1}$ falls by about $15-30 \mathrm{ml}$ per year and after age 50 this increases to $30-50 \mathrm{ml}$ per year. ${ }^{18}$ The magnitude of decline is slightly greater in men than women. ${ }^{18}$ In a summary of several studies, Kerstjens and colleagues concluded that men who were moderate to heavy smokers have, on average, a $15 \mathrm{ml}$ per year greater decline than non-smokers. The effect was slightly lower in women. ${ }^{18}$ Other risk factors for an accelerated decline in $\mathrm{FEV}_{1}$ from studies of general populations are airway hyper-responsiveness, atopy, childhood respiratory infections, air pollution, and occupational hazards. ${ }^{18}$ In addition, accelerated decline in FEV1 is likely to be present in many respiratory diseases. 
The finding of an association between decline in $\mathrm{FEV}_{1}$ and mortality in women adds to the similar findings in men reported in the two published studies. ${ }^{19}{ }^{20}$ In a (preliminary) report of a study that included both women and men $\mathrm{Xu}$ and colleagues found an association between decline in $\mathrm{FEV}_{1}$ and mortality that was stronger in women. ${ }^{21}$ The number and age range of the men included in the present study was similar to the men in the Baltimore Longitudinal Study of Aging $^{20}$ whereas the Honolulu Heart Program ${ }^{19}$ was larger (4000 subjects) and included only men aged 45 to 68 years. The study of $\mathrm{Xu}$ et $a l^{11}$ was also larger than our study with 2607 men and 3223 women but had a similar age range of 25 to 74 years. The time period when the cohorts were assembled and duration of follow up was similar in all three studies.

The magnitude of the effect in this study was that in women a $50 \mathrm{ml}$ per year increase in decline in $\mathrm{FEV}_{1}$ was associated with a $22 \%$ increase in the risk of death from all causes and in men an $8.2 \%$ increase in death from all causes. In the Honolulu Heart Program ${ }^{19}$ the relative risk for total mortality was 1.48 when comparing the tertile with the highest change in $\mathrm{FEV}_{1}$ (a decrease of $61 \mathrm{ml}$ per year) with the tertile with the lowest change in $\mathrm{FEV}_{1}$ (an increase of $9 \mathrm{ml}$ per year). In the Baltimore Health Study ${ }^{20}$ the relative risk for death resulting from cardiac disease was greater; the quintile with the highest decline in $\mathrm{FEV}_{1}$ had a relative risk of death of 3.27 compared with the quintile with the smallest decline in $\mathrm{FEV}_{1}$. In the study of $\mathrm{Xu}$ et $a l^{21}$ the average relative risk associated with an increase of $30 \mathrm{ml}$ per year in decline in $\mathrm{FEV}_{1}$ were 1.26 in women and 1.11 in men.

Rodrigues et al postulated four hypotheses to explain the association between decline in FEV $_{1}$ and mortality. ${ }^{19}$ Firstly, a larger decline in $\mathrm{FEV}_{1}$ leads to death from obstructive or non-obstructive respiratory diseases. This does not explain the association seen in the present study. There were too few deaths from respiratory disease in the Busselton cohort to analyse and the increased risk for death with greater decline in $\mathrm{FEV}_{1}$ was attributable to all causes of death that were predominantly cardiovascular disease and coronary heart disease although relative risks for these causes separately were not statistically significant. This probably reflects the size of the study. In the Baltimore Longitudinal Study of Aging the association was with cardiac death and independent of death because of lung disease. Secondly, it is possible that the increased change in $\mathrm{FEV}_{1}$ is a mark of existing disease that ultimately results in death. To avoid this problem deaths that occurred within three years of the final measurement of FEV1 were excluded from analysis. The Honolulu Heart Study was analysed with and without deaths occurring within the first five years of follow up; this comparison showed a similar pattern of association although the magnitude of the association was reduced when deaths within five years were excluded. ${ }^{19}$
Thirdly, the association between decline of $\mathrm{FEV}_{1}$ and total mortality could be because of confounding. The principal factor associated with decline in $\mathrm{FEV}_{1}$ and death is cigarette smoking and results are similar for all smoking categories apart from non-smoking men. The relative risk has been adjusted for asthma, which may be associated with an increased decline in $\mathrm{FEV}_{1}{ }^{29}$ and an increased risk of death. ${ }^{30}$ There is no obvious relation between cardiovascular risk factors and decline in $\mathrm{FEV}_{1}$. We were unable to adjust for factors such as air pollution, occupational hazards, airway hyperresponsiveness, and childhood respiratory infections, which have been associated with a more rapid decline in $\mathrm{FEV}_{1} \cdot{ }^{18}$ Air pollution is minimal in Busselton.

The fourth postulate was that $\mathrm{FEV}_{1}$ decline by itself contributes to the development and the progression of the disease that ultimately results in death predominantly because of cardiovascular disease. The mechanism of such a direct effect is not clear.

An association between $\mathrm{FEV}_{1}$ and mortality demonstrated in this study has been well reported. ${ }^{1-17}$ It has been suggested that the rate of the decline in $\mathrm{FEV}_{1}$ is greater in persons with a lower $\mathrm{FEV}_{1}$, the so called "horse racing effect" although this is debated. ${ }^{31}$ In this study the effect of decline in $\mathrm{FEV}_{1}$ on death was examined after adjusting for each subject's $\mathrm{FEV}_{1}$ using the average $\mathrm{FEV}_{1}$ of three measurements over the six year period.

Methodological factors that may influence the accuracy of the results include repeated measures of lung function, ascertainment of death and cause of death, and the selection and number of subjects studied. There are well recognised sources of error in the measurement of lung function and the study was performed before first publication of recommendations for standardisation of measurement of $\mathrm{FEV}_{1}{ }^{33}$ Period effects whereby the learning experience and perhaps changes in technique lead to a systematic increase in results that would tend to reduce the magnitude of decline in $\mathrm{FEV}_{1}$. The decline in $\mathrm{FEV}_{1}$ found in this group was similar to values previously reported. ${ }^{18}{ }^{32} \mathrm{~A}$ few deaths among people who have left the state of Western Australia may have been missed. The underlying cause of death was determined from the death certificates, which are sometimes inaccurate; in the other two published studies medical records of deceased subjects were reviewed by a panel of physicians to determine the cause of death. ${ }^{19}{ }^{20} \mathrm{~A}$ more accurate ascertainment of cardiac death may explain why a stronger association was seen in the Baltimore study in which there were 79 cardiac deaths from 883 subjects in the cohort whereas there were 81 deaths in 751 men attributed to coronary heart disease in our study. The subjects in this study were those who voluntarily attended two follow up assessments in a six year period and may not be representative of the community in general.

Therefore, this and other studies have shown that lung function, measured by $\mathrm{FEV}_{1}$, both as an absolute level and the rate of decline with age is a predictor of death from all causes and 
from cardiovascular disease. The mechanism of this relation between $\mathrm{FEV}_{1}$ and death is not understood but seems independent of tobacco smoking and other risk factors for cardiovascular diseases, which were the most common causes of death in the cohort studied.

The authors thank the Busselton Population Medical Research Foundation for access to the survey data, and the community of Busselton for their longstanding cooperation and support for the Busselton Health Study.

Funding: National Health and Medical Research Council of Australia.

Conflicts of interest: none.

1 Higgins MW, Keller JB. Predictors of mortality in the adult population of Tecumseh. Arch Environ Health $1970 ; 21: 418-24$

2 Kannel WB, Hubert H, Lew EA. Vital capacity as a predictor of cardiovascular disease: the Framingham Study. $A m$ Heart f 1983;105:311-15.

3 Beaty TH, Cohen BH, Newill CA, et al. Impaired pulmonary function as a risk factor for mortality. $A m \mathcal{F} E \mathrm{pi}$ demiol 1982;116:102-13.

4 Cullen K, Stenhouse NS, Wearne KL, et al. Multiple regression analysis of risk factors for cardiovascular disease and cancer mortality in Busselton, Western Australia: 13 year study. F Chron Dis 1983;36:371-7.

5 Peto R, Speizer FE, Cochrane AL, et al. The relevance in adults of air-flow obstruction, but not of mucus hypersecreadults of air-flow obstruction, but not of mucus hypersecretion, to mortality from chronic lung disease. Results from 20 years of prospecti

6 Krzyanowski M, Wysocki $M$. The relation of thirteen year mortality to ventilatory impairment and other respiratory symptoms: The Cracow Study. Int F Epidemiol 1986;15:5664.

7 Vollmer WM, McCamant LE, Johnson LR, et al. Respiratory symptoms, lung function and mortality in a screening center cohort. Am F Epidemiol 1989;129:1157-69.

8 Ebi-Kryston KL, Hawthorne VM, Rose G, et al. Breathlessness, chronic bronchitis and reduced pulmonary function as predictors of cardiovascular disease mortality among men in England, Scotland and the United States. Int 7 Epidemiol $1989 \cdot 18 \cdot 84-8$.

9 Ebi-Kryston KL. Predicting 15 year chronic bronchitis mortality in the Whitehall Study. $\mathcal{F}$ Epidemiol Community Health 1989;43:168-72.

10 Marcus EB, Curb JD, MacLean CJ, et al. Pulmonary function as a predictor of coronary heart disease. $A m \mathcal{F}$ 129:97-104.

11 Lange P, Nyboe J, Appleyard M, et al. Relation of ventilatory impairment and of chronic mucus hypersecretion to mortality from obstructive lung disease and from all causes. Thorax 1990:45:579-85.

12 Lange P, Nyboe J, Appleyard M, et al. Spirometric findings and mortality in never smokers. F Clin Epidemiol 1990;43. 867-73.
13 Kuller LH, Ockene J, Meilahn E, et al, for the Multiple Risk Factor Intervention Trial Research Group. Relation of forced expiratory volume in one second $\left(\mathrm{FEV}_{1}\right)$ to lung cancer mortality in the Multiple Risk Factor Intervention Trail (MRFIT). Am f Epidemiol 1990;132:265-74.

14 Strachan DP. Ventilatory function as a predictor of fatal stroke. BMF 1991;302:84-7.

15 Van den Eeden SK, Friedman GD. Forced expiratory volume (1 second) and lung cancer incidence and mortality. Epidemiology 1992;3:253-7.

16 Bang KM, Gergen PJ, Kramer R, et al. The effect of pulmonary impairment on all cause mortality in a national cohort. Chest 1993;103:536-40.

17 Hole DJ, Watt GC, Davey-Smith G, et al. Impaired lung function and mortality risk in men and women: findings from the Renfrew and Paisley prospective study. BMF 1996;313:711-15.

18 Kerstjens HAM, Rijcken B, Schouen JP, et al. Decline of $\mathrm{FEV}_{1}$ by age and smoking status: facts, figures and fallacies. Thorax 1997;52:820-7.

19 Rodriguez BL, Masaki K, Burchfiel C, et al. Pulmonary function decline and 17-year total mortality: The Honolulu Heart Program. Am 7 Epidemiol 1994;140:398-408.

20 Tockman MS, Pearson JD, Fleg JL, et al. Rapid decline in $\mathrm{FEV}_{1}$. A new risk factor for coronary heart disease mortality. Am F Respir Crit Care Med 1995;151:390-8.

$21 \mathrm{Xu}$ X, Dockery DW, Ware JH, et al. Decline of pulmonary function as a predictor of mortality in adults. Am Rev Respir Dis 1992;145:A198.

22 Cullen KJ. Mass health examinations in the Busselton population, 1966 to 1970 . Med F Aust 1972;2:714-18.

23 Webster IW. Busselton, a community study in cardiovascular disease. Aust NZ 7 Med 1974;4:412-14.

24 Knuiman MW, Cullen KJ, Bulsara MK, et al. Mortality trends, 1965 to 1989 , in Busselton, the site of repeated health surveys and interventions. Aust $f$ Public Health 1994;18:129-35.

25 Knuiman MW, Jamrozik K, Welborn TA, et al. Age and secular trends in risk factors for cardiovascular disease in Busselton. Aust f Public Health 1995;19:375-82.

26 Welborn TA, Cumptson GN, Cullen KJ, et al. The prevalence of coronary heart disease and associated factors in an Australian rural community. Am f Epidemiol 1969;89: $521-36$

27 Kalbfleisch JD, Prentice RL. The statistical analysis of failure time data. New York: Wiley, 1980.

28 SAS/STAT Software. Changes and enhancements through release 6.12. North Carolina, USA: SAS Institute Inc, 1997.

29 Peat JK, Woolcock AJ, CullenKJ. Rate of decline of lung function in subjects with asthma. Eur F Respir Dis 1987;70: 171-9.

30 Musk AW, Ryan GF, Perera DM, et al. Mortality from asthma in Western Australia. Med f Aust 1987;147:423-7.

31 Schoulen JP, Taper IB. Interpretation of longitudinal studies. Am f Respir Crit Care Med 1996;154:5278-84.

32 Ware JH, Dockery DW, Louis TA, et al. Longitudinal and cross sectional estimates of pulmonary function decline in never smoking adults. Am f Epidemiol 1990;132:685-700.

33 American Thoracic Society. Standardization of spirometry. Am Rev Respir Dis 1979;119:831-8. 